
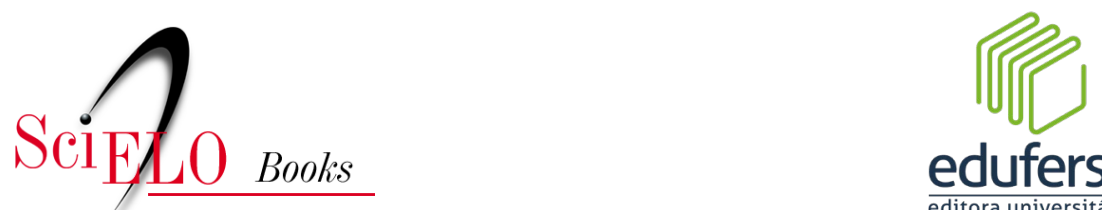

\title{
Capítulo 7 - A influência do SEBRAE na ação empreendedora do microempreendedor individual da cidade de Mossoró/RN
}

Niágara Aires Nogueira Ana Maria Magalhães Correia

\section{SciELO Books / SciELO Livros / SciELO Libros}

NOGUEIRA, N. A., and CORREIA, A. M. M. A influência do SEBRAE na ação empreendedora do microempreendedor individual da cidade de Mossoró/RN. In: OLIVEIRA, A. M. B., ed.

Empreendedorismo: registros de estudos teórico-empíricos no semiárido [online]. Mossoró: EdUFERSA, 2018, pp. 215-247. ISBN: 978-85-5757-090-0. https://doi.org/10.7476/9786587108667.0009.

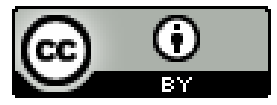

All the contents of this work, except where otherwise noted, is licensed under a Creative Commons Attribution 4.0 International license.

Todo o conteúdo deste trabalho, exceto quando houver ressalva, é publicado sob a licença Creative Commons Atribição 4.0. 


\title{
A INFLUÊNCIA DO SEBRAE NA AÇÃO EMPREENDEDORA DO MICROEMPREENDEDOR INDIVIDUAL DA CIDADE DE MOSSORÓ/RN
}

\author{
Niágara Aires Nogueira \\ Ana Maria Magalhães Correia
}

\subsection{Introdução}

As mudanças tecnológicas, suas inovações e a economia cobram dos empreendedores a postura de seguirem novos paradigmas, gerando emprego, criando novas relações de trabalho e desenvolvendo nossa sociedade (DORNELAS, 2005). Assim, a atuação empreendedora está profundamente incluída no contexto social e tecnológico no qual o empreendedor está inserido.

Nesse sentido, o tema empreendedorismo definitivamente ganhou espaço nos últimos anos, tanto no meio acadêmico, com a produção de inúmeros trabalhos, quanto nas discussões econômicas, no qual passou a ser considerado de importância relevante na formulação de políticas governamentais voltadas para o desenvolvimento dos países. Existe, atualmente, claro entendimento de que tanto a ação empreendedora quanto o agente responsável por ela, o empreendedor, são fundamentais para o crescimento econômico e para a geração de riqueza e empregos em uma sociedade (SILVA; GOMES; CORREIA, 2009).

Para Dornelas (2005), empreendedorismo é a junção de pessoas e processos que, integrados, resultam em ideias transformadas em oportunidades. E isso, em consequência, ocasiona a criação de novos negócios de sucesso. Nesse sentido, Schumpeter (1949, apud 
DORNELAS, 2005) afirma que o empreendedor é aquele que destrói a ordem econômica existente pela introdução de novos produtos e serviços, pela criação de novas formas de organização ou pela exploração de novos recursos e materiais.

Segundo o Serviço Brasileiro de Apoio às Micro e Pequenas Empresas ([SEBRAE], 2014), o empreendedor tem, como característica básica, o espírito criativo e pesquisador. Ele está constantemente buscando novos caminhos e novas soluções, sempre tendo em vista as necessidades das pessoas. A essência do empresário de sucesso é a busca de novos negócios e oportunidades, além da preocupação com a melhoria do produto. O Sebrae é um dos órgãos mais conhecidos do pequeno empresário brasileiro. É um serviço social autônomo, sem fins lucrativos, instituído por escritura pública, sob a forma de entidade associativa de direito privado (SEBRAE, 2014).

$\mathrm{Na}$ investida de formalizar e estimular os trabalhadores que estão na informalidade, foi criada a Lei Complementar $\mathrm{n}^{\circ}$ 128, de 19/12/2008, para a figura do Microempreendedor Individual (MEI), propiciando condições especiais para que o trabalhador conhecido como informal possa se tornar um MEI legalizado com apoio dos serviços do Sebrae. Além de uma forma de combater a informalidade, essa lei é uma oportunidade para instigar o empreendedorismo no país (SOUZA, 2010).

Segundo o Portal do Empreendedor, o número de empreendedores individuais no Brasil chegou a um número de 4.081.211 em 06 de junho de 2014. Esses acontecimentos mostram o interesse dos indivíduos em criar novos negócios e serem donos de sua própria fonte de renda. Nesse sentido, esses fatores despertam discussões a respeito do empreendedorismo, sobretudo, na cidade de Mossoró-RN, que encerrou 2013 com 4.403 empreendedores formalizados, ficando em segundo lugar no Rio Grande do Norte, perdendo posição para Natal, a capital do estado, com 17.571 optantes do Simples Nacional do MEI - SIMEI (PORTAL DO EMPREENDEDOR, 2014). 
Dessa forma, a legalização do MEI tem como expectativa tirar da informalidade milhões de trabalhadores que atuam por conta própria, por meio de desburocratização, redução de custos de legalização e de obrigações tributárias e trabalhistas. Segundo Silveira e Teixeira (2011), a alta carga tributária, aliada ao processo burocrático imposto pelas instituições, é um dos principais motivos de as pequenas e médias empresas do país serem informais.

Assim, o MEI surge para beneficiar milhares de trabalhadores informais que antes não possuíam enquadramento legal. No entanto, de acordo com o Sebrae (2014), o MEI restringe a participação de algumas atividades que não são acolhidas pela legislação, nas áreas da construção civil, decoração de interiores, paisagismo, serviços de conservação, vigilância e limpeza e serviços de natureza intelectual. Ainda ocorre de aqueles que possuem suas atividades propostas pelo MEI não serem enquadrados no caso de possuírem mais de um estabelecimento ou participarem de outra empresa como titular, administrador ou sócio, mesmo que este seja o cônjuge (SEBRAE, 2014).

Diante dessa realidade, observando a importância da formalização dos empreendedores para o desenvolvimento e o aperfeiçoamento dos empreendimentos inseridos no MEI, uma vez que essa formalização consiste em um processo complexo e que requer uma colaboração relevante do próprio empreendedor conjuntamente com as orientações e a atuação do Sebrae a partir das técnicas de gestão, surge o seguinte problema de pesquisa: Como se dá a influência do Sebrae na ação empreendedora em prol do desenvolvimento e da ampliação do negócio do microempreendedor individual da cidade de Mossoró/RN? 


\subsection{Revisão da literatura}

\subsubsection{Empreendedorismo}

O empreendedorismo é a envoltura de indivíduos que, unidos, induzem a mudança de ideias e oportunidades. É precisamente com o incentivo e a necessidade de depositar a prática em novas percepções que provocam a geração dos novos mercados bem sucedidos. O empreendedorismo é a mudança determinada pelo empreendedor. Essa palavra origina-se do termo francês "entrepreneur", que denota aquele que assume riscos e principia o novo (DORNELAS, 2005).

Assim, constata-se que o fenômeno empreendedorismo traz como agente o empreendedor, que é alguém capaz de desenvolver uma visão sobre negócios, é capaz de persuadir pessoas e identificar uma oportunidade de mercado onde os outros nada ou quase nada enxergam, além de ter energia, esperança e paixão pelo que faz (LANA et al., 2013). Embora pesquisas apontem as características que idealizem um modelo-padrão para discernir um empreendedor, tornar-se um é algo que pode acontecer com qualquer indivíduo.

Segundo Filion (1999), nenhuma tipologia é suficiente para atender a todos os tipos de empreendedores. Entretanto, elas formam uma base para a compreensão dos pontos que servem de apoio para o conhecimento comportamental desses indivíduos. Assim, em seu estudo, foram identificados seis tipos de perfil para o empreendedor de pequenas empresas. São eles:

- O lenhador: Esse empreendedor tem um perfil ambicioso e aptidão para trabalhar "duro" e não gosta de expor suas ideias para as outras pessoas, pois é muito focado. Se tem algo para fazer, realiza sem perder tempo. Quando trabalha para outras pessoas, chega a produzir até o dobro, destacando-se dos demais. 
É conhecido como trabalhador de sol a sol. Na condição de líder, é rigoroso com a qualidade e geralmente contrata pessoas que trabalhem diretamente com ele para que possa supervisionar o trabalho com mais rigor e, caso necessite, ensina ao contratado como fazer se não ficar satisfeito. Sua cultura organizacional é voltada para a produção e o seu perfil é o mais comum entre os empreendedores de pequenos negócios (FILION, 1999).

- O sedutor: $\mathrm{O}$ empreendedor sedutor geralmente se entrega de corpo e alma ao negócio, mas geralmente seu entusiasmo com ele não persiste muito. Lança um novo empreendimento no mercado e logo o vende ou compra companhias em dificuldades para que depois possa revende-las. É bastante sociável e possui uma vasta rede de contatos. Consegue identificar pontos fortes e fracos imediatamente em um negócio e, quando não está satisfeito com o investimento, por conhecer várias pessoas, repassa o negócio sem muitas dificuldades. Esse perfil é motivado por novidades e sua visão empresarial é direcionada diretamente ao lucro (FILION, 1999).

- O jogador: O perfil do empreendedor jogador é motivado pelo lazer. Vê o esporte como componente essencial em suas vidas. Não é comprometido com o que faz, geralmente trabalha muito em determinadas épocas do ano para estar mais tranquilo em outras. Trata o negócio como meio financeiro ou empecilho de praticar o que realmente ama. Normalmente, é uma pessoa de família rica, que passou sua juventude praticando esportes ou envolvido em diversas formas de lazer, que decidiu fazer o de que tanto gosta, o seu trabalho (FILION, 1999).

- O hobbysta: O empreendedor dessa classe dedica o seu tempo livre aos negócios. Normalmente, tem um trabalho oficial que, na maioria das vezes, é a fonte de investimento para fazer o de que tanto gosta. O seu negócio é o seu hobby. Em seu emprego 
oficial, geralmente trabalha em um nível intermediário e não toma decisões, o que não proporciona conhecimento para resolver problemas complexos, nem mesmo no seu próprio negócio. Futuramente, pode se transformar em um empreendedor lenhador ou jogador, desde que se realize fazendo aquilo de que gosta (FILION, 1999).

- O convertido: É aquele empreendedor que passou por muitas frustrações em relação a negócios anteriores, mas que, finalmente, encontrou o que tanto almejava e isso se tornará uma obsessão para ele. Ele depositará no empreendimento uma grande carga emocional e não saberá lidar com críticas que contrariem a sua vontade ou ações, mesmo que elas venham de pessoas próximas, como família e amigos. Ele acredita que outras pessoas estão perdendo tempo e dinheiro por não terem a mesma ideia ou não investirem em um negócio como o dele. Gosta de estar no controle e, por acreditar que o seu empreendimento é genial, gostaria de apresentar seus benefícios para a sociedade. Muitos criadores e inventores são caracterizados como convertidos. Em sua maioria, eles vieram de uma pesquisa em desenvolvimento, planejamento e marketing ou vendas e tem chances promissoras de se tornarem empreendedores missionários (FILION, 1999).

- O missionário: $\mathrm{O}$ empreendedor missionário, na maioria das vezes, iniciou seu negócio sozinho ou comprou seu atual empreendimento de terceiros e realizou mudanças essenciais para chegar aonde chegou. Conhece a fundo seu produto ou serviço, assim como o mercado em que está inserido. É consumido pelo que faz e sente muito prazer pelo que constrói. Após a fase de sobrevivência, fica aberto a novas ideias e se preocupa com o aprendizado e bem estar de seus colaboradores. Sempre inova em sua forma de trabalhar e faz questão de repassar suas ideias 
para quem trabalha com ele, provocando motivação e realização para si e os que estão em sua volta. Esse empreendedor tem forte tendência de expandir seu negócio para o exterior (FILION, 1999).

Filion (1999) conclui que, assim como o conceito de empreendedorismo, nenhuma tipologia é completa para definir todos os empreendedores existentes. Na sua visão, cada caso pode ser considerado único. Entretanto, as tipologias provêm uma base para a compreensão dos pontos de apoio, bem como dos valores e do pensamento dos empreendedores e as linhas para a compreensão da consistência comportamental geral dos atores.

\subsection{Características comportamentais empreendedoras (CCE'S)}

Atualmente, dois pontos se sobressaem nos estudos a respeito do empreendedor: o econômico e o comportamental (ZEN; FRACASSO, 2008). O ponto de vista econômico, apresentado por Schumpeter (1982), é relacionado à inovação. Para ele, os empreendedores causam a "destruição criativa", ação definida como impulso essencial que move e conserva a máquina capitalista, incessantemente inventando novos produtos, novos meios de produção e novos mercados, sobrepondo-se aos remotos processos menos eficientes e mais onerosos. Já a abordagem comportamental é associada a características dos empreendedores, representado por McClelland (1972) ao confrontar o conceito de empreendedor com o de sucesso, de prestígio, de influência e de controle.

Essa abordagem comportamental, resultado das pesquisas de McClelland (1972), contribuiu de forma mais significativa para o campo do empreendedorismo. McClelland (1972) indicou três necessidades peculiares dos empreendedores, conforme Quadro 8: a necessidade de realização pessoal, a principal necessidade mencionada entre os 
empreendedores bem sucedidos; a necessidade de poder e dominação; e a necessidade de afiliação, isso quando há pretensão de uma pessoa em principiar, manter ou renovar uma afinidade afetiva com outra.

Quadro 8 - Características comportamentais empreendedoras

\begin{tabular}{|c|c|}
\hline Necessidade & Características comportamentais empreendedoras \\
\hline \multirow{4}{*}{ Realização } & Busca de oportunidades e iniciativa \\
\cline { 2 - 2 } & Persistência \\
\cline { 2 - 2 } & Comprometimento \\
\cline { 2 - 2 } & Exigência de qualidade e eficiência \\
\cline { 2 - 2 } Planejamento & Correr riscos calculados \\
\cline { 2 - 2 } & Estabelecimento de metas \\
\cline { 2 - 2 } & Buanejamento e monitoramento sistemático \\
\hline \multirow{2}{*}{ Poder } & Persuasão e rede de contatos \\
\cline { 2 - 2 } & Independência e autoconfiança \\
\hline
\end{tabular}

Fonte: Adaptado do Sebrae (2005).

A necessidade pode ser relacionada à dimensão do coletivismo, para McClelland (1972), um "sintoma de preocupação na fantasia e na atividade real por tudo o que diz respeito a uma relação cordial e íntima entre as pessoas". Assim, o referido autor identificou, como principal força motivadora da atitude empreendedora, a "necessidade de realização do indivíduo" ou a vontade humana de se superar e tornar-se diferente, envolvendo características psicológicas e atitudinais, como tendência ao risco, iniciativa e desejo de reconhecimento.

Dessa forma, a necessidade de realização refere-se à busca de oportunidades e à suscetibilidade para realizar inovações, ser capaz de inventar e sustentar uma cadeia de contatos para bons relacionamentos. Essa necessidade, especialmente, demanda muita insistência e muito empenho. Isso insinua que o empreendedor precisa estar disposto a erros e acertos, sem perder suas obrigações e metas almejadas. A cobrança de qualidade e eficiência está bem presente na necessidade 
de realização, razão pela qual se deve sucessivamente procurar atender ou ultrapassar as perspectivas de prazo e qualidade. Havendo assim também a questão dos riscos, pois esses estão em qualquer atividade, contudo, necessitam ser avaliados, de forma bastante planejada, para minimizá-los (MCCLELLAND, 1972).

No tocante à necessidade de planejamento, o Sebrae (2005) faz referência ao estabelecimento de metas que o empreendedor estipula de curto e longo prazo. O benefício desse planejamento é que o empreendedor poderá determinar, com mais nitidez, os objetivos e as metas que proporcionem capacidade de atingir projetos mais abrangentes e contínuos. Com relação à sede de poder, está ligada à capacidade de persuasão, que é a habilidade de influenciar, que concerne em conseguir autonomia nas relações e a certeza de suas capacidades. No mais, essa questão indica que precisa conservar sua ótica ainda perante a obstinação ou os resultados que o deixem desmotivado.

Assim, McClelland (1972), em sua abordagem psicológica, define empreendedores ao relacioná-los à necessidade de sucesso, de reconhecimento e de desejo de poder e controle. Em suas pesquisas, de um modo geral, procura identificar o que fazem e como pensam os empreendedores bem sucedidos, visando estabelecer um ponto de partida para detectar e reforçar tais características em outros indivíduos. As primeiras pesquisas realizadas por esse autor apontaram, como principal força motivadora da atitude empreendedora, a "necessidade de realização do indivíduo". Isso corresponde à vontade humana de se superar e tornar-se diferente, envolvendo características psicológicas e atitudinais como, entre outras, tendência ao risco, iniciativa e desejo de reconhecimento (DEPIERI, 2005). 


\subsection{Microempreendor individual (MEI)}

O trabalho informal começou da necessidade dos trabalhadores que não conseguiam entrar ou regressar ao mercado de trabalho devido às dificuldades com que se deparavam no decorrer da procura por emprego ou até por alternativa própria, buscando continuamente aumentar a renda. Devido ao desenvolvimento do comércio informal, aconteceram algumas mudanças no Código Civil, por meio das quais diversos empreendedores definiram regularizar o seu empreendimento, por causa dos benefícios que essa regularização proporcionava (SEBRAE, 2014).

O microempreendedor individual é a pessoa que trabalha por conta própria e que se formaliza como pequeno empresário (PORTAL DO EMPREENDEDOR, 2014). No Brasil, os microempreendedores, até 2008, exerciam suas relações comerciais informalmente, por não haverem dado entrada na regularização das atividades. Posteriormente, com a promulgação da Lei do Microempreendedor e sua pouca burocracia, esse grupo obteve o direito à formalização do desenvolvimento de suas atividades econômicas e a proteção de alguns direitos básicos sociais, como: auxílio maternidade; auxílio doença; aposentadoria, entre outros. A Lei Complementar 128/2008, do Micro Empreendedor Individual, tem por objetivo promover ajustes na Lei Geral da Micro e Pequena Empresa, a Lei Complementar123/06. A Lei 128/2008 entrou em vigor em $1^{\circ}$ de julho de 2009, denominando o autônomo e o empresário individual como Microempreendedor Individual - MEI (PORTAL DO EMPREENDEDOR, 2014).

Os públicos-alvo dessa formalização do trabalho, por meio da MEI, são: ambulantes, cabeleireiros, manicures, marceneiros, eletricistas, feirantes, encanadores, pedreiros, mecânicos, pintores, sapateiros, pipoqueiros, dentre outros de diversos segmentos (RELATÓRIO SEBRAE PERFIL EMPREENDEDOR, 2013). 
O microempreendedor individual tem responsabilidades pela tributação de pessoa física e jurídica. Contudo, é interessante elucidar que estas nunca poderão ser confundidas. É a pessoa jurídica quem cobrirá os impostos essenciais às suas atividades e, no caso de possuir empregados em seu empreendimento, recolhem-se o INSS, ICMS/ISS, dependendo do segmento da atividade e permanecendo isento pela LC $n^{\circ} 128 / 08$ de emitir os pagamentos do PIS, CONFINS, CSLL e IPI e INSS Patronal (SOUZA, 2010).

A formalização é gratuita e pode ser realizada por intermédio dos escritórios de contabilidade optantes pelo Simples Nacional, pelo Sebrae, escritórios de contabilidade ou pelo próprio microempreendedor. $\mathrm{O}$ registro do MEI precisará ser realizado por meio da internet, pelo portal do empreendedor. Desse modo, após a formalização do MEI, o empreendedor individual passa a contar com benefícios previdenciários e seus períodos de carência, de acordo com o Portal Empreendedor (2014): aposentadoria por invalidez, aposentadoria por idade; aposentadoria especial e aposentadoria por tempo de contribuição; auxílio-doença e auxílio-acidente; salário-família e salário-maternidade. Por fim, os dependentes do MEI terão direito a pensão morte e auxílio reclusão.

Ao regularizar seu negócio, o empreendedor tem a oportunidade de suplantar os problemas financeiros que afetam seu empreendimento. A formalização diminui a insegurança jurídica do negócio, do modo a consentir que a atividade seja em local legalizado, havendo alvarás de funcionamento e sanitário. Igualmente, faz com que o empreendedor possa comprovar sua renda, podendo, portanto, abrir conta bancária, ter acesso a crédito financeiro, dentre outros benefícios.

No tocante ao faturamento, o limite máximo para o enquadramento na MEI é de uma receita bruta anual de até $\mathrm{R} \$ 60.000,00$. Outro ponto importante é que o MEI só poderá contratar um único funcionário e este deverá receber o piso salarial da categoria profissional ou um salário mínimo. Sobre o alvará de funcionamento, os estabelecimentos 
empresariais são permitidos a funcionar pelas prefeituras. Para isso, os empreendedores precisam estar atentos às peculiaridades do seu município para que todos os processos relacionados ao alvará de funcionamento aconteçam em concordância com a previsão legal (PORTAL DO EMPREENDEDOR, 2014).

\subsection{Procedimentos metodológicos}

Essa pesquisa busca explanar a problemática referente à influência do Sebrae na ação empreendedora em prol do desenvolvimento e da ampliação do negócio do microempreendedor individual da cidade de Mossoró/RN. Com isso, buscou-se a realização do estudo no Escritório Regional do Oeste - Sebrae em Mossoró/RN, onde os MEI’s foram formalizados e desenvolvem suas atividades.

Assim, esta pesquisa enquadra-se como aplicada quanto a sua natureza, exploratória e descritiva quanto aos seus objetivos e qualitativa quanto à forma de abordagem do problema, tanto no que se refere à forma de abordar o fenômeno quanto no que diz respeito à maneira como foi estruturado. Gomes e Araújo (2005) defendem que isso se explica pelo fato de esse tipo de pesquisa propiciar a obtenção de resultados mais fidedignos, uma vez que, nessa tipologia metodológica, prioriza-se a qualidade em detrimento da quantidade. Vale salientar que as informações quantitativas que são apresentadas neste estudo, tais como médias ou percentuais, serviram apenas como demonstração dos dados obtidos, não invalidando, assim, a sua natureza qualitativa.

É caracterizada também por um estudo de caso, pois se fundamenta no estudo intenso de um ou poucos objetos, no caso, os microempreendedores individuais da cidade de Mossoró/RN, de modo que consinta seu vasto e detalhado conhecimento. Segundo Gil (2010, p. 58), o estudo de caso é caracterizado pelo estudo profundo e exaustivo de um ou de poucos objetos, de maneira a permitir o seu conhecimento amplo 
e detalhado, tarefa praticamente impossível mediante os outros tipos de delineamentos considerados.

O tipo de amostragem utilizada foi a não probabilística, com base no critério de acessibilidade ou intencionalidade. Nesse sentido, do universo de 4.569 MEI's cadastrados no Sebrae Mossoró/RN, essa pesquisa apresenta resultados com base na amostra de 154 microempreendedores individuais (Quadro 9), que responderam ao questionário estruturado de forma presencial ou através de e-mail, no período de outubro a dezembro do ano de 2014.

A coleta dos dados se deu por meio de um questionário estruturado, composto de duas partes. A parte I teve por objetivo identificar o perfil do microempreendedor individual e as opiniões acerca do desenvolvimento e das melhorias alcançadas pelo empreendedor a partir da procura por sua regularização. Já na parte II, os respondentes foram questionados quanto à autoavaliação do perfil empreendedor e da influência do Sebrae nas competências gerenciais dos entrevistados.

Assim, para a análise do questionário na parte II, utilizou-se a "Escala de Likert", mediante a qual os pesquisados responderam a cada quesito por intermédio de vários graus de concordância. O nível de concordância dos questionários em relação aos fatores investigados foi enumerado mediante uma escala formada por cinco pontos equidistantes, sendo o $1^{\circ} \mathrm{e} o 2^{\circ}$ ponto correspondentes à insuficiente e fraco, o $3^{\circ}$ correspondente à regular, o que se pode considerar como um ponto imparcial, e os $4^{\circ}$ e $5^{\circ}$ pontos correspondentes a bom e a excelente. 
Quadro 9 - Quantitativo dos MEI's quanto à área de atividade

\begin{tabular}{|c|c|}
\hline Área de atividade dos microempreendedores individuais & Quantidade \\
\hline Ambulante & 19 \\
\hline Cabelereiro (a) & 43 \\
\hline Costureira & 3 \\
\hline Eletricista & 2 \\
\hline Proprietário (a) de mini mercado & 2 \\
\hline Proprietário (a) de restaurante & 18 \\
\hline Proprietário (a) de casas de chá, lanchonetes & 13 \\
\hline Comerciante de artigos de perfumaria & 17 \\
\hline Comerciante de artigos de vestuário e acessórios & 28 \\
\hline Comerciante de bebidas & 9 \\
\hline Total & 154 \\
\hline
\end{tabular}

Fonte: Dados da pesquisa (2014).

A análise e a interpretação dos dados constituem um processo que envolve vários procedimentos e análises que requerem a interpretação dos dados. Essa interpretação visa estabelecer a ligação entre os resultados obtidos e outros já conhecidos, derivados de teorias ou de estudos anteriores (GIL, 2010). Nesse sentido, com base nos objetivos deste estudo, os dados coletados foram analisados de acordo com o modelo de abordagem interpretativa, tendo em vista que esse tipo de abordagem tem como finalidade a busca pelo sentido mais amplo da resposta (GIL, 2010).

\subsection{Apresentação e análise dos dados}

Para um melhor entendimento, a apresentação e a análise dos resultados está dividida nas duas partes do questionário: a primeira trata da caracterização dos microempreendedores respondentes do questionário, e a segunda parte apresenta a autoavaliação do perfil empreendedor e a influência do Sebrae em suas competências gerenciais, focalizando os itens abordados no instrumento de coleta da pesquisa. 


\subsubsection{Parte I - Caracterização dos MEI`s}

\subsubsection{Quanto à faixa etária è à escolaridade}

De acordo com as informações obtidas pelos questionários, pode-se perceber que os microempreendedores individuais apresentaram um total de 57 respondentes, com idade de 31 a 40 anos, 38 com idade de 41 a 50 anos, 37 com idade de 21 a 30 anos. Nesse sentido, é possível verificar microempreendedores individuais com idades de 21 a 50 anos, que já desenvolvem atividades relacionadas a seu negócio próprio.

Com relação ao nível de escolaridade apresentado obtido pelas respostas, observa-se que mais de 70 indivíduos, do total de trabalhadores pesquisados, têm o ensino médio completo, sendo este o nível de escolaridade que predomina na maior parte dos microempreendedores individuais formalizados e analisados nesta pesquisa. Percebe-se também que uma pequena parte da amostra se especializou em uma atividade por meio do ensino superior ou técnico, 8 e 3, respectivamente. Observam-se ainda 35 respondentes com nível de escolaridade médio incompleto e uma quantidade significativa de 27 respondentes que cursaram apenas o ensino fundamental, necessitando de auxílio e capacitação para gerenciar seus negócios.

\subsubsection{Quanto aos motivos que levaram os MEl's a investirem no empreendimento}

O desejo de ter o próprio negócio foi bastante relevante para $66 \mathrm{mi}-$ croempreendedores individuais na cidade de Mossoró/RN, seguido da afinidade pela atividade, com 49 respondentes, e da dificuldade de conseguir emprego, com 37 respondentes. Houve também uma pequena quantidade de 3 respondentes que informou, como motivo, $o$ incentivo de amigos e familiares. 
Com isso, McClelland (1972) identifica, como principal força motivadora da atitude empreendedora, a "necessidade de realização do indivíduo" ou a vontade humana de se superar e tornar-se diferente. Dessa forma, a necessidade de realização refere-se à busca de oportunidades e à suscetibilidade para realizar inovações, capazes de inventar e sustentar uma cadeia de contatos para bons relacionamentos.

\subsubsection{Quanto às facilidades para formalização do MEI}

Com relação às facilidades para formalização do MEI, perguntou-se aos microempreendedores individuais como estes tomaram conhecimento do Programa MEI. Quase metade, ou seja, 76 respondentes, soube do programa por meio de métodos de capacitação do Sebrae. Além disso, 48 dos respondentes informaram que conheceram o programa pela televisão, por meio de propagandas relacionadas com o Sebrae ou envolvendo suas parcerias, e apenas 18 respondentes afirmaram que $o$ conhecimento se deu por meio da internet. Dessa forma, observa-se um trabalho significativo do Sebrae, do governo e de entidades envolvidas em relação à divulgação da Lei Complementar no 128, de 19/12/2008 para a figura do microempreendedor individual, propiciando condições especiais para que o trabalhador conhecido como informal possa se tornar um MEI legalizado, com apoio dos serviços do Sebrae.

Nesse sentido, é possível verificar que o Sebrae buscou, de forma ostensiva, noticiar o MEI, disponibilizando a esses microempreendedores ferramentas indispensáveis para solucionar suas dúvidas e captar informações indispensáveis para que possa escolher, de forma consciente, pela sua formalização. O Sebrae fornece atendimento gratuito para a orientação e a formalização desses microempreendedores individuais. 


\subsubsection{Quanto aos meios de conhecimento sobre o MEI}

Com relação aos meios de conhecimento sobre o MEI, os 102 respondentes informaram que encontraram informação facilmente no Sebrae e assim realizaram a formalização no mesmo momento. Além disso, 28 respondentes obtiveram conhecimento por outros meios, formalizando-se por intermédio do site do Portal Empreendedor ou por meio de um contador, e 18 respondentes informaram que necessitaram retornar várias vezes em busca de conhecimento para se sentirem seguros sobre a formalização.

Sobre os respondentes que buscaram informações várias vezes para regularizarem suas atividades, apresentando dificuldades ou insegurança, faz-se necessário que estes procurem, por outros meios, profissionais ou entidades para obterem informações mais compreensíveis. Apesar de representar um número pequeno em relação aos outros MEI's, evidencia ainda a necessidade, por parte dos órgãos competentes como o Sebrae, de ter mais ferramentas para proporcionar informações mais detalhadas e de fácil entendimento aos microempreendedores que buscam esses esclarecimentos e ajuda para sua formalização.

\subsubsection{Quanto aos benefícios que motivaram o microempreendedor à formalização e os que tiveram maior contribuição no dia-a-dia das atividades}

Com relação aos benefícios encontrados que motivaram o microempreendedor a obter formalização, verifica-se que 83 respondentes informaram que foi com relação ao benefício dos direitos previdenciários, 24 respondentes informaram que foi o benefício de poder emitir nota fiscal e possuir comprovação de renda e 18 respondentes informaram que foi com relação ao benefício da obtenção da redução dos impostos e obrigações exigidas. 
Esse resultado demonstra, com relação à maior quantidade que afirmou a busca de direitos previdenciários, que o trabalhador informal não está amparado por nenhuma segurança previdenciária em caso de acidente ou de problema de saúde resultante do trabalho, assim como não é contemplado pelos demais benefícios que comumente são cedidos aos trabalhadores assalariados. Nesse sentido, com a formalização por meio do MEI, o empreendedor individual passa a ser protegido com alguns benefícios previdenciários, como já citados. Sendo assim, o microempreendedor individual enxerga, na formalização de seu negócio, a oportunidade de trabalhar dentro da legalização, procurando o seu desenvolvimento e o de seu negócio, apresentando novos conhecimentos, ou complementando suas experiências.

Com relação a quais desses benefícios tiveram maior contribuição no dia-a-dia das atividades, verifica-se que, apesar do benefício de obtenção dos direitos previdenciários ter sua maioria, obteve segunda colocação nesse item, com 57 dos respondentes. Nesse sentido, o benefício de realização pessoal e profissional obteve a maior quantidade, com 64 dos respondentes marcando essa opção. Verificam-se ainda 19 respondentes que afirmaram facilidades no acesso ao crédito e financiamentos e 13 respondentes que afirmaram redução dos impostos e das obrigações exigidas.

Para esse resultado, observa-se que os dois benefícios que foram de maior relevância para os pequenos empreendedores, o de realização pessoal e profissional, refletem que o desejo de ter o próprio negócio, além de uma forma de subsidiar a renda e o sustento, o negócio pode trazer satisfação para este indivíduo. Para isso, McClelland (1972) afirma, em seus estudos sobre as características comportamentais empreendedoras, que a necessidade de realização pessoal é a principal necessidade mencionada pelos empreendedores bem sucedidos. E o benefício dos direitos previdenciários mostra que, além de ser o motivo que os motivaram a formalizar, também é o benefício considerado de 
maior contribuição no desenvolvimento das atividades, pelas razões já informadas no item anterior.

\subsubsection{Quanto às vendas após a formalização e à contribuição do Sebrae para os resultados obtidos}

Quanto à indagação se, após a formalização, as vendas aumentaram, diminuíram ou se foi indiferente, a maioria dos respondentes, ou seja, 123, responderam que aumentaram as vendas após a formalização. Dessa forma, verifica-se que é um número bastante significativo quanto à relevância do programa para o desenvolvimento dessas atividades e ao estimulo à regularização das empresas. Apesar disso, 27 dos respondentes afirmaram que foi indiferente, ou seja, nem aumentaram nem diminuíram as vendas.

Assim, em termos de porcentagem, dos 123 respondentes que afirmaram que as vendas aumentaram, 27 responderam que as vendas aumentaram em 20\%, 8 responderam que aumentaram em 30\%, 14 responderam aumentaram em 40\%, 18 responderam aumentaram em 50\%, 13 responderam que aumentaram em 60\%, 12 responderam aumentaram em 80\%, 14 responderam que aumentaram em 100\% e 17 responderam aumentaram em mais de $100 \%$. Contudo, foi possível observar que, embora os resultados estejam visualizados, de acordo com a resposta dos MEI's, percebeu-se uma dificuldade de conhecimentos sobre o real aumento dessas vendas, inclusive reconhecido por eles mesmos no que se refere à mensuração das vendas. Com isso, pode-se inferir o desconhecimento por parte dos respondentes acerca dessa questão.

Com isso, complementando essa questão, foi indagado aos MEI's qual a ação deles junto ao Sebrae para o resultado desse aumento das vendas. Como resultado positivo, chegando a um consenso sobre as respostas, houve o reconhecimento desses microempreendedores de que conseguiram aumentar suas vendas após a formalização, por se- 
guirem os ensinamentos adquiridos em capacitações e as orientações fornecidas pelo Sebrae. Já no que se refere ao não aumento das vendas, o resultado da conclusão para essas respostas foi de que os MEI's que se formalizaram no Sebrae apenas procuraram a instituição para a regularização da empresa e não especificamente para ações de capacitação em vendas ou de que afirmaram que, mesmo com as ações, o ritmo de vendas não foi alterado após a formalização.

\subsubsection{Quanto à satisfação com a formalização e o desenvolvimento da atividade e com as ações do Sebrae após a formalização}

Com relação à satisfação com a formalização e o desenvolvimento da atividade, observa-se que 137 dos respondentes afirmaram estar satisfeitos por optarem pela formalização e reconhecem o desenvolvimento dessa atividade após essa ação, enquanto que 17 dos respondentes afirmaram não estar satisfeitos com a formalização e com o desenvolvimento da atividade. $\mathrm{O}$ êxito, para o microempreendedor, pode ser avaliado pela liberdade e pelo equilíbrio de seu negócio, o que favorecerá melhor qualidade de vida (PORTAL DO EMPREENDEDOR, 2014).

Com relação à satisfação com as ações do Sebrae para com o microempreendedor individual após a formalização, os dados demonstram que 123 respondentes estão satisfeitos com as ações do Sebrae, enquanto 31 respondentes afirmaram não estarem satisfeitos.

Esse resultado corrobora com o item anterior e mostra que o objetivo do Sebrae em auxiliar na formalização do microempreendedor individual está sendo cumprido e gerando resultados satisfatórios. Nesse sentido, a influência do Sebrae com relação aos 154 microempreendedores individuais é positiva e satisfatória, acarretando maior autonomia, manutenção de seu ponto de vista, mesmo diante da oposição ou de resultados inicialmente desanimadores, e confiança na sua própria capacidade de completar uma tarefa difícil ou de enfrentar um desafio. 
Para finalizar essa fase, foi perguntado aos microempreendedores individuais o que o Sebrae poderia melhorar para o desenvolvimento dos MEI's e, como resposta, obtiveram-se as seguintes afirmações: 119 microempreendedores afirmaram estar satisfeitos e não deram nenhuma sugestão; 16 não responderam; 4 sugeriram haver uma maior atenção ou acompanhamento com os MEI's; 2 sugeriram realizar mais eventos voltados para esses empreendedores; 2 citaram a necessidade de propagar casos de sucessos para surgir ideias; 2 sugeriram mostrar opções de ideias; 1 sugeriu fazer parcerias com as autoridades para reduzir os impostos; 3 sugeriram criar uma associação para os MEI's, um dos quais especificou sua sugestão de uma associação por segmento de mercado; 1 sugeriu que o valor das consultorias fosse mais acessível e 4 sugeriram uma parceria com os bancos para facilitar o crédito.

Nesse panorama, é importante ressaltar que essas opiniões abrangeram também os MEI's que estão na condição de satisfeitos, indiferentes e não satisfeitos com os serviços prestados, mas que quiseram dar sua contribuição quanto a suas ações para o desenvolvimento dos negócios. Dessa forma, essas sugestões serão enviadas aos responsáveis para as devidas avaliações e adequações que se fizerem necessárias.

\subsubsection{Parte II - Avaliação do perfil empreendedor e influência do Sebrae nas competências gerenciais dos MEl's}

Para compor essa avaliação, o questionário de pesquisa objetivou conhecer a influência do Sebrae nas competências gerenciais dos microempreendedores individuais, nas áreas de marketing, operações/ produção, finanças, administração, relacionamento interpessoal/equipes e quais habilidades específicas não estavam listadas nas áreas já citadas, com relação a uma autoavaliação e à importância para a empresa. 


\subsubsection{Autoavaliação referente ao marketing}

Com relação à autoavaliação referente ao marketing, conforme Tabela 19, é possível observar que a área de marketing, para esses pequenos microempreendedores individuais, é bastante considerada na sua autoavaliação e de importância para a empresa, com a grande maioria dos respondentes tecendo opiniões entre excelente e bom, no que se refere a avaliação e pesquisa de mercado, planejamento de marketing, estabelecimentos de preços dos produtos, gerenciamento de vendas, vendas por catálogo/mala-direta, telemarketing, serviço ao consumidor, gerenciamento de distribuição, planejamento de novos produtos e venda direta.

Embora o termo marketing não seja muito conhecido por esses microempreendedores, e sim o termo propaganda, segundo eles próprios, percebe-se que, desde o item 1 até o item 10 da área de marketing, a grande maioria informou que a influência do Sebrae sobre essa área é considerada excelente e boa tanto para a sua avaliação quanto para a empresa.

Tabela 19 - Autoavaliação referente ao marketing

(continua)

\begin{tabular}{|c|c|c|c|c|c|c|c|c|c|c|}
\hline \multirow[b]{2}{*}{ Competências gerenciais } & \multicolumn{5}{|c|}{ Sua avaliação } & \multicolumn{5}{|c|}{$\begin{array}{c}\text { Importância para sua } \\
\text { empresa }\end{array}$} \\
\hline & 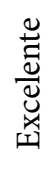 & ฐี & 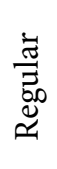 & 莺 & 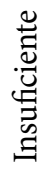 & 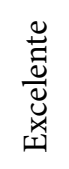 & ह̊ & 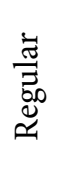 & 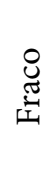 & 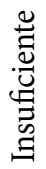 \\
\hline & 5 & 4 & 3 & 2 & 1 & 5 & 4 & 3 & 2 & 1 \\
\hline
\end{tabular}

Marketing

1. Avaliação e pesquisa de mercado.

$\begin{array}{llllllllll}56 & 64 & 21 & 8 & 5 & 55 & 65 & 21 & 8 & 5\end{array}$

2. Planejamento de marketing. $\begin{array}{lllllllllll}43 & 88 & 19 & 2 & 2 & 43 & 88 & 19 & 2 & 2\end{array}$

3.Estabelecimento de preços dos produtos.

$\begin{array}{llllllllll}59 & 74 & 11 & 8 & 2 & 59 & 74 & 11 & 8 & 2\end{array}$ 


\begin{tabular}{|c|c|c|c|c|c|c|c|c|c|c|}
\hline \multirow{3}{*}{ Competências gerenciais } & \multicolumn{5}{|c|}{ Sua avaliação } & \multicolumn{5}{|c|}{$\begin{array}{c}\text { Importância para sua } \\
\text { empresa }\end{array}$} \\
\hline & 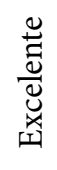 & घี & 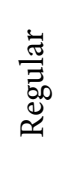 & 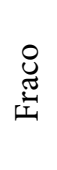 & 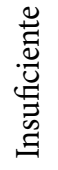 & 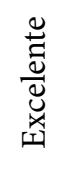 & हี & 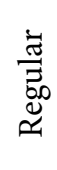 & 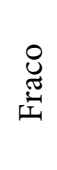 & 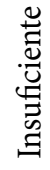 \\
\hline & 5 & 4 & 3 & 2 & 1 & 5 & 4 & 3 & 2 & 1 \\
\hline 4. Gerenciamento de vendas. & 54 & 73 & 17 & 3 & 7 & 54 & 73 & 17 & 3 & 7 \\
\hline $\begin{array}{l}\text { 5. Venda por catálogo/mala } \\
\text { direta. }\end{array}$ & 12 & 16 & 3 & 0 & 0 & 12 & 16 & 3 & 0 & 0 \\
\hline 6. Telemarketing. & 17 & 23 & 12 & 2 & 0 & 17 & 23 & 12 & 2 & 0 \\
\hline 7. Serviço ao consumidor. & 42 & 80 & 23 & 9 & 0 & 42 & 80 & 23 & 9 & 0 \\
\hline $\begin{array}{l}\text { 8. Gerenciamento de } \\
\text { distribuição. }\end{array}$ & 23 & 57 & 24 & 16 & 7 & 23 & 57 & 24 & 16 & 7 \\
\hline $\begin{array}{l}\text { 9. Planejamento de novos } \\
\text { produtos. }\end{array}$ & 53 & 57 & 19 & 9 & 16 & 54 & 56 & 19 & 9 & 16 \\
\hline 10. Venda direta. & 67 & 53 & 16 & 6 & 12 & 67 & 53 & 16 & 6 & 12 \\
\hline
\end{tabular}
Fonte: Dados da pesquisa (2014).

Diante disso, segundo o Sebrae (2014), a capacitação na área de marketing envolve o evento O Negócio é o Seguinte. Esse evento aborda temas de importância para o microempreendedor individual, como compras, vendas, cooperação, planejamento, marketing e finanças.

\subsubsection{Autoavaliação referente às operações/produção}

Com relação à autoavalição referente à área de operações/produção, na Tabela 20, é possível observar que, para os microempreendedores individuais, a área de operações/produção também é bastante considerada na sua autoavaliação e quanto à importância para a empresa. Embora grande parte dos respondentes tenha considerado excelente a participação do Sebrae nesse contexto, a parcela maior dos respondentes afirmou como boa essa influência, no que se refere a gerenciamento 
da manufatura, controle de estoques, controle de análises de custos, planejamento e produção e compras de matérias-primas.

Tabela 20 - Autoavaliação referente às operações/produção

\begin{tabular}{|c|c|c|c|c|c|c|c|c|c|c|}
\hline \multirow{3}{*}{ Competências gerenciais } & \multicolumn{5}{|c|}{ Sua avaliação } & \multicolumn{5}{|c|}{$\begin{array}{l}\text { Importância para sua } \\
\text { empresa }\end{array}$} \\
\hline & 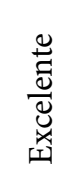 & ‡్ & 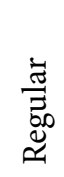 & 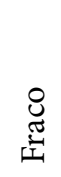 & 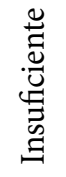 & 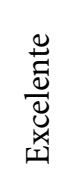 & घี & 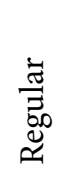 & 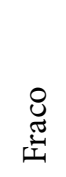 & 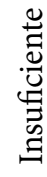 \\
\hline & 5 & 4 & 3 & 2 & 1 & 5 & 4 & 3 & 2 & 1 \\
\hline \multicolumn{11}{|l|}{ Operações/Produção } \\
\hline $\begin{array}{l}\text { 1. Gerenciamento da } \\
\text { manufatura }\end{array}$ & 23 & 84 & 32 & 8 & 7 & 22 & 85 & 32 & 8 & 7 \\
\hline 2. Controle de estoques & 27 & 99 & 18 & 6 & 4 & 27 & 99 & 18 & 6 & 4 \\
\hline $\begin{array}{l}\text { 3. Controle e análise de } \\
\text { custos }\end{array}$ & 23 & 64 & 45 & 19 & 3 & 21 & 66 & 19 & 45 & 3 \\
\hline $\begin{array}{l}\text { 4. Planejamento de } \\
\text { Produção }\end{array}$ & 56 & 87 & 8 & 2 & 1 & 55 & 88 & 8 & 2 & 1 \\
\hline $\begin{array}{l}\text { 5. Compra de matérias- } \\
\text { primas }\end{array}$ & 49 & 41 & 34 & 19 & 11 & 53 & 38 & 33 & 19 & 11 \\
\hline
\end{tabular}

Fonte: Dados da pesquisa (2014).

Dessa forma, percebe-se que, desde o item 1 até o item 5 da área de operações/produção, a grande maioria informou que a influência do Sebrae sobre essa área é considerada boa e excelente tanto para a sua avaliação quanto para a empresa. Assim, diante de muitas indagações, entende-se que uma boa atuação nessa área visa compreender o surgimento de oportunidades para a criação de produtos e serviços, mercados novos, novas formas e processos de produção, medidas de como utilizar, de forma eficiente, a matéria-prima e as tecnologias existentes, além de entender como os indivíduos exploram e desenvolvem esses meios (BARON, 2010). 


\subsubsection{Autoavaliação referente às finanças}

Com relação à autoavaliação referente ao marketing, conforme Tabela 21, é possível observar que a área de finanças, para esses pequenos microempreendedores individuais, é considerada importante para a sua autoavaliação e para a empresa. Porém, obteve uma variação de respondentes tecendo opiniões entre excelente, bom e regular, no que se refere a contabilidade, orçamentos, gerenciamento de fluxo de caixa, gerenciamento de contas a pagar e receber, gerenciamento das relações com fontes de financiamento, negociação para obtenção de recursos financeiros, contratos, impostos, seguros e patentes e propriedade intelectual.

Apesar dessa variação, é possível perceber a importância dessa área para os microempreendedores e uma influência relativamente positiva por parte do Sebrae aos MEI's. Nesse mesmo item, observa-se que nenhum dos microempreendedores considerou insuficiente a influência da instituição para esse aspecto.

Tabela 21 - Autoavaliação referente às finanças

(continua)

\begin{tabular}{|c|c|c|c|c|c|c|c|c|c|c|}
\hline \multirow{3}{*}{ Competências gerenciais } & \multicolumn{5}{|c|}{ Sua avaliação } & \multicolumn{5}{|c|}{$\begin{array}{c}\text { Importância para sua } \\
\text { empresa }\end{array}$} \\
\hline & 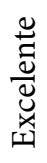 & $\underset{0}{\Xi}$ & 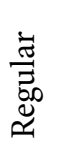 & 菉 & 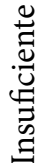 & 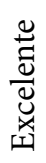 & 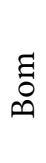 & 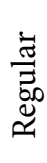 & 莺 & 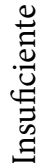 \\
\hline & 5 & 4 & 3 & 2 & 1 & 5 & 4 & 3 & 2 & 1 \\
\hline
\end{tabular}

Finanças

1. Contabilidade

2. Orçamentos

3. Gerenciamento de fluxo de caixa

$\begin{array}{llllllllll}57 & 33 & 27 & 24 & 13 & 57 & 33 & 27 & 24 & 13\end{array}$

$\begin{array}{llllllllll}56 & 77 & 19 & 2 & 0 & 56 & 77 & 19 & 2 & 0\end{array}$

$\begin{array}{llllllllll}63 & 47 & 29 & 12 & 3 & 63 & 47 & 29 & 12 & 3\end{array}$ 


\begin{tabular}{|c|c|c|c|c|c|c|c|c|c|c|}
\hline \multirow{3}{*}{ Competências gerenciais } & \multicolumn{5}{|c|}{ Sua avaliação } & \multicolumn{5}{|c|}{$\begin{array}{c}\text { Importância para sua } \\
\text { empresa }\end{array}$} \\
\hline & 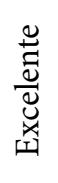 & घี & 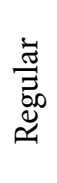 & 莺 & 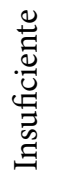 & 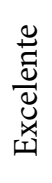 & हี & 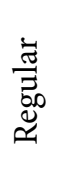 & 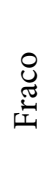 & 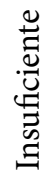 \\
\hline & 5 & 4 & 3 & 2 & 1 & 5 & 4 & 3 & 2 & 1 \\
\hline $\begin{array}{l}\text { 4. Gerenciamento de contas a } \\
\text { pagar e a receber }\end{array}$ & 62 & 42 & 21 & 17 & 12 & 62 & 42 & 21 & 17 & 12 \\
\hline $\begin{array}{l}\text { 5. Gerenciamento das } \\
\text { relações com fontes de } \\
\text { financiamento }\end{array}$ & 59 & 47 & 29 & 12 & 7 & 59 & 47 & 29 & 12 & 7 \\
\hline $\begin{array}{l}\text { 6. Negociação para obtenção } \\
\text { de recursos financeiros }\end{array}$ & 7 & 21 & 7 & 1 & 5 & 7 & 21 & 7 & 1 & 5 \\
\hline 7. Contratos & 0 & 0 & 0 & 0 & 0 & 0 & 0 & 0 & 0 & 0 \\
\hline 8. Impostos & 7 & 2 & 0 & 0 & 0 & 7 & 2 & 0 & 0 & 0 \\
\hline 9. Seguros & 0 & 0 & 0 & 0 & 0 & 0 & 0 & 0 & 0 & 0 \\
\hline $\begin{array}{l}\text { 10. Patentes e propriedade } \\
\text { intelectual }\end{array}$ & 2 & 1 & 0 & 0 & 0 & 2 & 1 & 0 & 0 & 0 \\
\hline
\end{tabular}

Fonte: Dados da pesquisa (2014).

Dessa forma, cabe ao Sebrae enfatizar aos microempreendedores individuais a necessidade de se buscar auxílio quanto a informações sobre inovação, gestão, finanças, sustentabilidade, bem como de participar de programas desenvolvidos pelo Sebrae, visando a retenção de clientes, qualificação e desenvolvimento do produto/serviço, fatores essenciais para a permanência do negócio no mercado.

\subsubsection{Autoavaliação referente às rotinas administrativas}

Com relação à autoavaliação referente à área de administração no que envolve as ações nas rotinas administrativas, conforme Tabela 
22, é possível observar que a área administrativa, para esses pequenos microempreendedores individuais, é bastante considerada na sua autoavaliação e quanto à importância para a empresa, com a grande maioria dos respondentes tecendo opiniões entre excelente e bom, no que se refere a resolução de problemas, comunicação, planejamento, tomada de decisão, gerenciamento de projetos, negociação, administração pessoal e sistema de informação gerencial.

Tabela 22 - Autoavaliação referente às rotinas administrativas

\begin{tabular}{|c|c|c|c|c|c|c|c|c|c|c|}
\hline \multirow{3}{*}{ Competências gerenciais } & \multicolumn{5}{|c|}{ Sua avaliação } & \multicolumn{5}{|c|}{$\begin{array}{l}\text { Importância para } \\
\text { sua empresa }\end{array}$} \\
\hline & 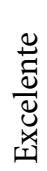 & ‡్̃ & 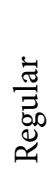 & 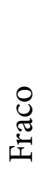 & 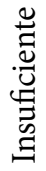 & 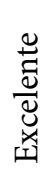 & 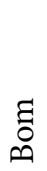 & 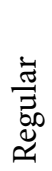 & 莺 & 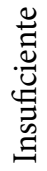 \\
\hline & 5 & 4 & 3 & 2 & 1 & 5 & 4 & 3 & 2 & 1 \\
\hline
\end{tabular}

Rotinas administrativas

1. Resolução de problemas

$\begin{array}{llllllllll}56 & 83 & 10 & 3 & 2 & 56 & 83 & 10 & 3 & 2\end{array}$

2. Comunicação

$\begin{array}{llllllllll}81 & 57 & 11 & 4 & 1 & 81 & 57 & 11 & 4 & 1\end{array}$

3. Planejamento

$\begin{array}{llllllllll}58 & 66 & 19 & 7 & 4 & 58 & 66 & 19 & 7 & 4\end{array}$

4. Tomada de decisão

$\begin{array}{llllllllll}49 & 73 & 21 & 6 & 5 & 49 & 73 & 21 & 6 & 5\end{array}$

5. Gerenciamento de projetos

$\begin{array}{llllllllll}19 & 23 & 9 & 5 & 17 & 19 & 23 & 9 & 5 & 17\end{array}$

6. Negociação

$\begin{array}{llllllllll}55 & 34 & 21 & 7 & 4 & 55 & 34 & 21 & 7 & 4\end{array}$

7. Administração pessoal

$\begin{array}{llllllllll}21 & 26 & 7 & 2 & 2 & 21 & 26 & 7 & 2 & 2\end{array}$

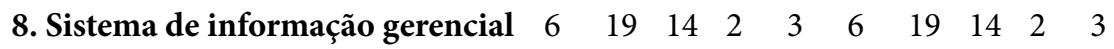

Fonte: Dados da pesquisa (2014).

Embora essa seja uma área bastante complexa, percebe-se que, desde o item 1 até $\mathrm{o}$ item 8 da área administrativa, a grande maioria informou que a influência do Sebrae sobre essa área é considerada excelente e boa tanto para a sua avaliação quanto para a empresa. 
Dornelas (2005) ainda afirma que o empreendedor planejado seria, entre todos, o mais completo do ponto de vista da caracterização de empreendedor e que deveria ser seguido como referência.

\subsubsection{Autoavaliação referente ao relacionamento interpessoal/equipes}

Com relação à autoavaliação referente ao relacionamento interpessoal/ equipes, conforme Tabela 23, é possível observar que essa área de relacionamento, para esses pequenos microempreendedores individuais, é bastante considerada na sua autoavaliação e quanto à importância para a empresa, porém com uma quantidade baixa de respondentes tecendo opiniões entre excelente e bom. Apenas 12, dos 154 microempreendedores, responderam aos itens questionados. Isso se dá pelo fato de a grande maioria dos MEI's operarem suas atividades sozinhas ou com, no máximo, um trabalhador com carteira assinada, segundo a Lei 128/2008 do Microempreendedor Individual.

Embora hajam sido obtidas poucas respostas com relação a essa autoavaliação, percebe-se que, desde o item 1 até o item 7 da área de relacionamento interpessoal/equipes, a grande maioria que respondeu informou que a influência do Sebrae sobre essa área é considerada excelente e boa tanto para a sua avaliação quanto para a empresa. 
Tabela 23 - Autoavaliação referente ao relacionamento interpessoal/equipe

\begin{tabular}{|c|c|c|c|c|c|c|c|c|c|c|}
\hline \multirow[b]{2}{*}{ Competências gerenciais } & \multicolumn{5}{|c|}{ Sua avaliação } & \multicolumn{5}{|c|}{$\begin{array}{l}\text { Importância para } \\
\text { sua empresa }\end{array}$} \\
\hline & 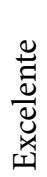 & ઘ̊ & 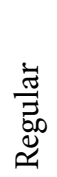 & 总 & 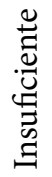 & 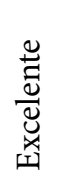 & ‡్ & $\frac{\vec{z}}{\overrightarrow{3}}$ & 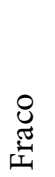 & 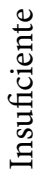 \\
\hline & 5 & 4 & 3 & 2 & 1 & 5 & 4 & 3 & 2 & 1 \\
\hline \multicolumn{11}{|c|}{ Relacionamento interpessoal/equipes } \\
\hline 1.Liderança/visão/influência & 6 & 6 & & & & 6 & 6 & & & \\
\hline 2. Ajuda e coaching & 7 & 5 & & & & 5 & 7 & & & \\
\hline 3.Feedback & 7 & 5 & & & & 7 & 5 & & & \\
\hline 4.Gerenciamento de conflitos & 2 & 4 & 1 & 2 & 3 & 2 & 4 & 1 & 2 & 3 \\
\hline 5. Gerenciamento de pessoas & 7 & 5 & & & & 7 & 5 & & & \\
\hline 6. Trabalho em equipe & 7 & 5 & & & & 7 & 5 & & & \\
\hline $\begin{array}{l}\text { 7. Construção de equipes de } \\
\text { trabalho }\end{array}$ & 6 & 6 & & & & 6 & 6 & & & \\
\hline
\end{tabular}
Fonte: Dados da pesquisa (2014).

Todavia, de acordo com o Sebrae (2014), mesmo com essa limitação no quadro de colaboradores, os poucos envolvidos no negócio devem avaliar oportunidades, identificar, buscar e alocar os recursos necessários ao negócio, planejar as ações a serem tomadas, implementar e gerenciar o novo negócio.

Por fim, foi sugerido aos microempreendedores individuais que eles explanassem outros fatores nos quais o Sebrae tenha contribuído para o desenvolvimento de suas atividades que não foram expostos pelo instrumento de pesquisa. Apenas 1 empreendedor respondeu a essa questão, explanando um fator que contribuiu positivamente tanto para sua avaliação quanto para seu empreendimento, que foi referente às capacitações de oratória. Esse único fator foi avaliado no nível 5, considerado excelente no que se refere à dificuldade de falar em público sanada pelas orientações fornecidas pelo Sebrae. 


\subsection{Considerações finais}

A pesquisa realizada com os microempreendedores individuais da cidade de Mossoró/RN teve como objetivo analisar a influência do Sebrae na ação empreendedora desses pequenos empresários. A pesquisa cumpriu o objetivo a que se propôs, ao perceber que a influência do Sebrae na ação empreendedora em prol do desenvolvimento e DA ampliação do negócio do microempreendedor individual decorre da procura desses indivíduos pelos recursos oferecidos pela instituição. Nesse sentido, por parte da organização responsável por fomentar esse desenvolvimento, é feito um trabalho de sensibilização a partir de eventos, feiras, apoios em programas de desenvolvimento de responsabilidade municipal, estadual e nacional, bem como da disponibilidade da própria estrutura para receber esses empreendedores. Desse modo, foi verificado um alto índice de satisfação com relação ao programa do MEI e às ações do Sebrae realizadas após essa formalização.

Embora os resultados da autoavaliação se apresentem positivos no tocante às contribuições para o conhecimento em competências gerenciais fornecidos pelo Sebrae, tanto para esses microempreendedores individuais quanto para seu empreendimento, verificou-se uma ruptura na continuação da prestação desses serviços por conta da falta de interesse dos próprios microempreendedores em procurar orientação e capacitação no Sebrae. Nesse sentido, a justificativa dada pelos MEI's é que essa ausência da procura por conhecimentos, capacitação e orientação dos microempreendedores ocorra pelo fato de conduzirem os negócios sozinhos. Mesmo nessa situação, o Sebrae dispõe de recursos que sanem esses obstáculos, como cursos online, ensino a distância (EaD), visitas para consultorias, orientações por meio de telefone, e-mail e mídias sociais, bastando apenas haver a procura por parte dos microempreendedores individuais. 


\section{REFERÊNCIAS}

BARON, R. A. Empreendedorismo: Uma visão do processo. São Paulo: Cengage Learning, 2010.

DEPIERI, C.C.L.S. Atitude empreendedora e cultura: um estudo em organizações brasileiras. 2005. 94 f. Dissertação (Mestrado em Administração)-Programa de Pós-Graduação em Administração. Universidade de Brasília. Brasília, 2005.

DORNELAS, J. C. A. Empreendedorismo: transformando ideias em negócios. 2. ed. Rio de Janeiro: Elsevier, Ed. Campus, 2005.

FILION, L. J. Empreendedorismo: empreendedores e proprietáriosgerentes de pequenos negócios. RAUSP - Revista de Administração da Universidade de São Paulo, v. 34, n. 2, p. 5-28, 1999.

GIL, A. C. Como elaborar projetos de pesquisa. 5. ed. São Paulo: Atlas, 2010.

GOMES, F. P.; ARAÚJO, R. M. Pesquisa quanti-qualitativa em administração: uma visão holística do objeto em estudo. In: SEMEAD - SEMINÁRIO EM ADMINISTRAÇÃO, 8, 2005, São Paulo (SP). Anais... São Paulo (SP): FEA/USP, 2005. Sem paginação. Disponível em: http://www.ead.fea.usp.br/Semead/8semead/ resultado/trabalhosPDF/152.pdf. Acesso em: 10 dez. 2014.

LANA, J. et al. A relação das competências empreendedoras e da conduta intraempreendedora no setor de serviços educacionais. RPCA - Revista Pensamento Contemporâneo em Administração, v. 7, n. 2, p. 77-95, 2013. 
MCCLELLAND, D. C. A sociedade competitiva: realização e progresso social. Rio de Janeiro: Expressão e Cultura, 1972.

RELATÓRIO SEBRAE - PERFIL DO MICROEMPREENDEDOR INDIVIDUAL. Empreendedores. 2013. Disponível em: $<$ http:// www.sebrae.com.br/sites/PortalSebrae/estudos_pesquisas/GEM2013:-recorde-de-empreendedores-por-oportunidade,detalhe,29>. Acesso em: 21 nov. 2014.

PORTAL DO EMPREENDEDOR. Microempreendedor individual. 2014. Disponível em: $<$ http://www.portaldoempreendedor.gov.br/ mei-microempreendedor-individual>. Acesso em: 16 maio 2014. SCHUMPETER, J. A. Teoria do desenvolvimento econômico: uma investigação sobre capital, crédito, juro e o ciclo econômico. Tradução de Maria Silvia Possas. São Paulo: Abril Cultural, 1982. SERVIÇO BRASILEIRO DE APOIO A MICRO E PEQUENAS EMPRESAS (SEBRAE). Manual do Empresário. 2005. Vitória: SEBRAE/ES. Disponível em: <http://www.sebrae.com.br $>$. Acesso em: 01 maio 2014.

SERVIÇO BRASILEIRO DE APOIO A MICRO E PEQUENAS EMPRESAS (SEBRAE). Quem Somos. 2014. Disponível em $<$ http://www.sebrae.com.br/sites/PortalSebrae/ufs/df/quem_ somos?codUf=7>. Acesso em 27 nov. 2014.

SILVA, M. A. O. M.; GOMES, L. F. A. M.; CORREIA, M. F. Cultura e orientação empreendedora: uma pesquisa comparativa entre empreendedores em incubadoras no Brasil e em Portugal. RAC Curitiba, v. 13, n. 1, p. 57-71, 2009.

SILVEIRA, J. P.; TEIXEIRA, M. R. C. Empreendedor individual e os impactos pós-formalização. São Paulo: UNIPAM, 2011. 
SOUZA, D. M. Os principais benefícios proporcionados ao trabalhador informal para a formalização através do Microempreendedor Individual. 2010. 95 f. Monografia do Curso de Ciências Contábeis. Universidade Federal de Santa Catarina UFSC, 2010.

ZEN, A. C.; FRACASSO, E. M. Quem é o empreendedor? As implicações de três revoluções tecnológicas na construção do termo empreendedor. RAM - Revista de Administração Mackenzie, v. 9, n. 8, edição especial, p. 135-150, 2008. 
Editora Universitária da UFERSA (EdUFERSA)

Av. Francisco Mota, 572

Compl.: Centro de Convivência

Costa e Silva - Mossoró/RN - CEP: 59.625-900

(84) 3317-8267

http://edufersa.ufersa.edu.br

edufersa@ufersa.edu.br

Formato: PDF

Números de páginas: 247 